\title{
Hydrophobin-nanofibrillated cellulose stabilized emulsions for encapsulation and release of BCS class II drugs
}

\section{Paukkonen, Heli}

2017-03-30

Paukkonen, H , Ukkonen, A , Szilvay , G, Yliperttula , M \& Laaksonen , T 2017 , ' Hydrophobin-nanofibrillated cellulose stabilized emulsions for encapsulation and release of BCS class II drugs ' , European Journal of Pharmaceutical Sciences , vol. 100 , pp. 238-248 . https://doi.org/10.1016/j.ejps.2017.01.029

http://hdl.handle.net/10138/297780

https://doi.org/10.1016/j.ejps.2017.01.029

cc_by_nc_nd

acceptedVersion

Downloaded from Helda, University of Helsinki institutional repository.

This is an electronic reprint of the original article.

This reprint may differ from the original in pagination and typographic detail.

Please cite the original version. 
1 Hydrophobin-nanofibrillated cellulose stabilized emulsions for encapsulation and release of BCS class II drugs

Heli Paukkonen a , Anni Ukkonen a , Geza Szilvay ${ }^{\text {b }}$, Marjo Yliperttula ${ }^{\text {a,c }}$, Timo Laaksonen ${ }^{\text {a,d }}$

${ }^{a}$ Division of Pharmaceutical Biosciences, Faculty of Pharmacy, University of Helsinki, P.O. Box

5 56, FI-00014 Helsinki, Finland

${ }^{\mathrm{b}}$ VTT Technical Research Centre of Finland, P.O. Box 1000, FI-02044 VTT Espoo, Finland

${ }^{c}$ Department of Pharmaceutical and Pharmacological Sciences, via Marzalo 5, University of

8 Padova, Padova, Italy

${ }^{\mathrm{d}}$ Department of Chemistry and Bioengineering, Tampere University of Technology, P.O. Box 541, FI-33101 Tampere, Finland

\section{ABSTRACT}

The purpose of this study was to construct biopolymer-based oil-in-water emulsion formulations for encapsulation and release of poorly water soluble model compounds naproxen and ibuprofen. Class II hydrophobin protein HFBII from Trichoderma reesei was used as a surfactant to stabilize the oil/water interfaces of the emulsion droplets in the continuous aqueous phase. Nanofibrillated cellulose (NFC) was used as a viscosity modifier to further stabilize the emulsions and encapsulate protein coated oil droplets in NFC fiber network. In our previous study it has been shown that hydrophobin proteins and NFC can be used successfully to stabilize oil-in-water emulsions (Varjonen et al., Soft Matter 7, 2011, 2402-2411). In this study the use of these materials has been extended for stabilization of pharmaceutical emulsions. The potential of both native and oxidized NFC were studied for this purpose. Various emulsion formulations were prepared and the abilities of different formulations to control the drug release rate of naproxen and ibuprofen, used as model compounds, were evaluated. The optimal formulation for sustained drug release consisted of $0.01 \%$ of drug, $0.1 \%$ HFBII, $0.15 \%$ oxidized NFC, $10 \%$ soybean oil and $90 \%$ water phase. By comparison, the use of native NFC in combination with HFBII resulted in an immediate drug release for both of the compounds. The results indicate that these NFC originated biopolymers are suitable for pharmaceutical emulsion formulations. The native and oxidized NFC grades can be used as emulsion stabilizers in sustained and immediate drug release applications. Furthermore, stabilization of the emulsions was achieved with low concentrations of both HFBII and NFC, which may be an advantage when compared to surfactant concentrations of conventional excipients traditionally used in pharmaceutical emulsion formulations. 
1 Nanofibrillated cellulose; Hydrophobin; Emulsions; Drug release; Ibuprofen; Naproxen

\section{Abbreviations}

BC, bacterial cellulose; BCS, biopharmaceutical classification system; DLS, dynamic light scattering; GIT, gastrointestinal tract; HFBII, class II hydrophobin protein HFBII; IBU, ibuprofen; NAP, naproxen; NFC, nanofibrillated cellulose; NFC-N, native nanofibrillated cellulose; NFC-O, TEMPO oxidized nanofibrillated cellulose; PDI, polydispersity index; pI, isoelectric point

\section{Introduction}

Oral administration route is the preferred drug delivery route for chronic therapy due to its high patient compliance and ease of administration when compared to the parenteral routes. The bioavailability of orally administered poorly water soluble biopharmaceutical classification system (BCS) class II drugs is limited by their solubility in the varying conditions of the gastrointestinal tract (GIT) (Khadra et al., 2015). Consequently this may result in poor bioavailability. Several formulation strategies have been developed to tackle the solubility limitation including soluble complexes, emulsions and selfemulsifying systems (Fahr, 2007;Singh et al., 2011). In lipid based drug delivery systems the drug molecules are solubilized in the formulation, which is beneficial for consistent bioavailability of poorly water soluble drugs. Emulsion formulation strategies have been used to increase the aqueous solubility of poorly soluble drugs and to control the required bioavailability of these drugs (Gao et al., 1998;Gorain et al., 2014;He et al., 2011).

Emulsions are widely used as pharmaceutical dosage forms as the emulsified materials may obtain advantages such as improved bioavailability and masking of poor organoleptic properties when compared to other dosage forms. Typically pharmaceutical emulsions are used for oral, topical or intravenous administration routes. However, emulsions are thermodynamically unstable and therefore must be stabilized by addition of an emulsifying agent. Several emulsifying agents can be used depending on the type of emulsion that is produced (Strickley, 2004). The use of traditional pharmaceutical emulsifiers may be limited by their concentration dependent toxicity (Davis et al., 1970;Gloxhuber, 1974). In general, orally administered nonionic and anionic surfactants are low in toxicity but compatibility with skin and mucous membranes is concentration dependent (Gloxhuber, 1974).

Typically used nonionic surfactants in pharmaceutical dosage forms include Tweens, Spans, Cremphors and Pluronic block copolymers. However, these compounds may interfere with the 
absorption of certain drugs due to the inhibition of various efflux pumps and transporters present in the GIT (Rege et al., 2001;Rege et al., 2002;Woodcock et al., 1992). The drug absorption may be increased if the surfactants affect the functionality of efflux pumps. This may affect the desired bioavailability levels of certain drug compounds that are substrates for efflux pumps or transporters in the GIT. In food industry proteins in addition to emulsifiers are widely used in emulsion stabilization (Wilde et al., 2004). Proteins stabilize emulsions due to their interfacial properties and the ability to form viscoelastic layers at interfaces. Natural biopolymers, such as proteins, offer an alternative to synthetic excipients used in the stabilization of pharmaceutical emulsions.

Development of nanotechnology has enabled the production of nanocellulose from the natural polymer cellulose. Nanocellulose term applies to nanofibrillated cellulose (NFC), bacterial cellulose (BC) and cellulose nanocrystals (Klemm et al., 2011). Plant materials such as wood pulp are commonly used starting materials for NFC preparation. Typically the production includes mechanical fibrillation of native cellulose before and/or after enzymatic or chemical pretreatment. The diameter of native NFC (NFC-N) fibers is typically 5-60 nm and the length is several micrometers. The NFC$\mathrm{N}$ surface chemistry, hemicellulose content, fiber dimensions and the proportions of crystalline and amorphous regions may vary depending on the origin of cellulose as well as nanofibrillation processing (Klemm et al., 2011;Lin and Dufresne, 2014). NFC-N from plant materials may have hemicelluloses and lignin as accompanying impurities on the surface of the fibrils (Fall et al., 2011). Hemicellulose contains carboxyl groups and on the surface of NFC-N it introduces a surface charge to the NFC fibers due to the deprotonation of carboxyl groups.

Cellulose can be generally considered to be biocompatible due to moderate, if any, foreign responses in vivo (Märtson et al., 1999;Miyamoto et al., 1989). Additionally, NFC has been shown to be nontoxic in various in vitro cell models (Hannukainen et al., 2012;Hua et al., 2014;Vartiainen et al., 2011). Plant derived NFC-N and BC have been used in various biomedical applications such as drug delivery, skin tissue repair and tissue bioscaffolds for cellular culture (Kolakovic et al., 2012;Kolakovic et al., 2013;Malinen et al., 2014;Rouabhia et al., 2014). Plant derived native NFC-N is a promising matrix material for controlled drug release applications due to its high surface area to its volume ratio and the multiple carboxyl binding sites on the surface of NFC-N fibers that can interact with drug molecules via electrostatic interactions (Kolakovic et al., 2013). The electrostatic binding of molecules with carboxyl groups present on the surface of NFC-N is $\mathrm{pH}$ dependent. Electrostatic interactions between negatively charged carboxyl groups present in NFC-N and positively charged drugs has been seen as the main binding mechanism for these drugs (Kolakovic et al., 2013). However, drug interactions with NFC driven by other mechanisms such as aromatic $\pi$ 
stacking and hydrogen bonding might still take place regardless of the charge of the molecule. The surface of NFC can be activated via TEMPO [(2,2,6,6-Tetramethylpiperidin-1-yl)oxyl] oxidation to contain negatively charged carboxyl groups as binding sites for various macromolecules such as peptides and enzymes (Weishaupt et al., 2015). This approach enables the immobilization of drugs and macromolecules by electrostatic interactions due to the high density of negative charges on the surface of TEMPO oxidized NFC (NFC-O). The NFC-O fibers have typically 3-4 nm diameter and the length in the range of few micrometers (Saito et al., 2006;Saito et al., 2007). Furthermore, NFCO has been shown to be nontoxic in in vitro cell models (Alexandrescu et al., 2013;Hua et al., 2014).

Hydrophobin proteins (HFBs) are a group of small about $10 \mathrm{kDa}$ amphiphilic fungal proteins that are capable of lowering the interfacial tension by self-assembly into monolayers at hydrophobic/hydrophilic interfaces such as air-water $(\mathrm{a} / \mathrm{w})$ and oil-water $(\mathrm{o} / \mathrm{w})$ (Linder et al., 2005; Linder, 2009; Paananen et al., 2013). Due to this property HFBs have the ability to convert hydrophobic surfaces into hydrophilic ones and vice versa (Lumsdon et al., 2005;Szilvay et al., 2007). HFBs are nontoxic by themselves which is a prerequisite for pharmaceutical excipients (Ebbole, 1997). Additionally, a surface layer of HFB on the airborne fungal spores has been shown to prevent immune recognition (Aimanianda et al., 2009). This is an attractive feature for materials in pharmaceutical applications. Based on differences in biophysical properties and hydropathy patterns HFBs are divided into class I and class II HFBs (Linder, 2009). Class II Trichoderma reesei HFBs (e.g., HFBI, HFBII and HFBIII) are more water soluble than class I HFBs and can be easily dissolved at rather high concentrations (at least $100 \mathrm{mg} / \mathrm{ml}$ ) in aqueous solutions (Kisko et al., 2008;Linder et al., 2005). The amphiphilic nature of HFBs is attributed to the existence of a hydrophobic patch on the surface of otherwise fairly hydrophilic surface of HFB monomers (Linder et al., 2005). The overall structure therefore resembles the structure of surfactants with one hydrophobic and one hydrophilic part. The amphiphilicity makes HFBs suitable surface coating materials for pure drug crystals as well as drug carrier materials. HFBs have been successfully used as surfactants, encapsulating agents for nutraceuticals and coatings for drug nanoparticles (NPs) (Israeli-Lev and Livney, 2014;Sarparanta et al., 2012; Valo et al., 2010). HFBII coating on the surface of drug NPs has been shown to introduce mucoadhesive properties to drug NPs in the GIT (Sarparanta et al., 2012). For poorly water soluble drugs, mucoadhesive formulations are beneficial for improving drug bioavailability due to the prolonged time at the site of drug absorption.

Recently NFC has been used in combination with HFBs to produce emulsions, stabilize drug nanocrystals and to produce aerogel matrices for HFB coated drug NPs (Valo et al., 2011; Valo et al., 2013; Varjonen et al., 2011). It has been shown in our previous study that HFBs and NFC can be used 
successfully to stabilize o/w emulsions (Varjonen et al., 2011). Surface active HFB fusion proteins that contained cellulose-binding domains from cellulolytic enzymes were used. By combining the fusion protein HFBs and NFC emulsions that contained tightly packed thin NFC films at the oil/water interface were obtained. In this study Trichoderma reesei HFBII and NFC were used for the stabilization of pharmaceutical emulsions. Due to the interesting surface properties, low toxicity and good biocompatibility of both NFC and HFBII, these materials were selected for the production of $\mathrm{o} / \mathrm{w}$ emulsion formulations.

The emulsions were used for the encapsulation and release of poorly water soluble BCS II drugs naproxen (NAP) and ibuprofen (IBU). HFBII was used as a surfactant to stabilize the o/w interface of the emulsions, whereas NFC was added to modify the viscosity of the continuous aqueous phase. The addition of NFC polymer increases the viscosity of the continuous phase in o/w emulsions as well as w/o/w emulsions and creates a polymer network that limits drop collision, thus reducing the coalescence phenomena (Carrillo et al., 2015;Dimic-Misic et al., 2013;Garti, 1999;Xhanari et al., 2011). Furthermore, the bending of hydrophilic NFC at the $\mathrm{o} / \mathrm{w}$ interface favors positive curvature towards the organic oil-phase and results in water continuous o/w emulsions (Binks, 2002). These properties were exploited for emulsion stabilization. The effect of the amount of NFC, HFBII and their combinations on the emulsion stability was studied. After the preliminary formulation optimization, the most suitable formulations were selected for the drug release studies. The two different grades of NFC, native and oxidized, were expected to induce differences in the drug release profiles.

\section{Materials and methods}

\subsection{Materials}

Hydrophobin class II protein HFBII from Trichoderma reesei was provided by VTT Technical Research Centre of Finland, Finland. Native (Growdex $\left.{ }^{\circledR} 1.73 \%\right)$ and oxidized $(0.56 \%)$ nanofibrillated cellulose hydrogels (NFC-N and NFC-O, respectively) were kindly provided by UPM-Kymmene Corporation, Finland. Cellulose kraft pulp was chemically modified and fibrillated to form NFC hydrogels (Saito et al., 2006; Saito et al., 2007). Due to birch based raw material the NFC-N used in this work contained some soluble hemicelluloses. This hemicellulose fraction attributes to the slightly anionic surface charge of NFC-N. Higher negative charge of NFC-O is generated by the carboxyl groups directly on the fiber surface (carboxylic acid content $1.02 \mathrm{mmol} / \mathrm{g}$ pulp). $5 \mathrm{mg} / \mathrm{ml} \mathrm{stock}$ solutions of HFBII and NFC-N were prepared in ultrapure water. NFC-O was used at the provided concentration of $5.6 \mathrm{mg} / \mathrm{ml}$. Soybean oil (batch no. MKBN8800V) and ethyl oleate (batch no. 
BCBL9739V) were purchased from Sigma-Aldrich, USA and UK respectively. NAP and IBU were

2 purchased from Sigma-Aldrich, USA and China respectively. $1 \mathrm{mg} / \mathrm{ml}$ stock solutions of IBUand

3 NAP were prepared in soybean oil. Solubility of IBUand NAPin soybean oil was confirmed by

4 nephelometry (data not shown) (Nepheloscan Ascent, Labsystems, Finland). Acetonitrile was of

5 analytical grade, Sigma-Aldrich, Germany. Phosphate salts used in the preparation of $0.1 \mathrm{M} \mathrm{pH} 7.4$

6 phosphate buffer were of analytical grade, Sigma-Aldrich, Germany. Whatman $0.4 \mu \mathrm{m}$ pore size

7 Track-Etch polycarbonate membranes were used as semipermeable membranes in the

8 diffusionstudies, Sigma-Aldrich, Germany.

\subsection{Methods}

\subsubsection{Emulsion preparation method}

Emulsions were prepared from combinations of ultrapure water, soybean oil, ethyl oleate, HFBII 5 $\mathrm{mg} / \mathrm{ml}$ stock solution, NFC-N $5 \mathrm{mg} / \mathrm{ml}$ stock solution and NFC-O $5.6 \mathrm{mg} / \mathrm{ml}$ stock solution. To prevent aggregation in an aqueous environment, HFBII stock solution was sonicated first for 10 minutes before preparing the emulsions. All formulations were premixed by repeated pipetting in eppendorf tubes prior to ultrasound-sonication. The final emulsion volume was $1 \mathrm{ml}$ for all emulsion formulations and the volume of the oil phase was $10 \%$. The ultrasound-sonication based method for the preparation of emulsions was described in our previous study (Varjonen et al., 2011). The same method was used in this study with minor modifications. The sonication was performed with a high intensity ultrasound processor (Sonics, USA) equipped with a $2 \mathrm{~mm}$ stepped microprobe (power 750 $\mathrm{W}$, frequency $20 \mathrm{kHz}$ and amplitude 30\%). During 4 x 30 seconds of sonication the samples were kept in an ice bath. After the sonication the samples were homogenized in an ultrasonic bath for 1 hour. For high-shear mixing tests, a process time of 1-4 minutes was used (25 000rpm, Ultra-Turrax T8, IKA WERKE, Germany). In NAP and IBU formulations the drug was dissolved in soybean oil in $1 \mathrm{mg} / \mathrm{ml}$ concentration prior to the emulsion preparation. Table 1 summarizes the different formulations and their specific contents. 7

(1)

9
0 31 
1 Table 1. Emulsion formulation codes and contents. NAP and IBU containing formulations were 2 prepared based on preliminary formulations.

\begin{tabular}{|c|c|c|c|c|c|c|c|}
\hline Formulation code & $\begin{array}{c}\text { HFBII } \\
(\mathrm{mg} / \mathrm{ml})\end{array}$ & $\begin{array}{l}\text { NFC-N } \\
(\mathrm{mg} / \mathrm{ml})\end{array}$ & $\begin{array}{l}\mathrm{NFC}-\mathrm{O} \\
(\mathrm{mg} / \mathrm{ml})\end{array}$ & $\begin{array}{c}\text { Soybean oil } \\
(10 \%)\end{array}$ & $\begin{array}{c}\text { Ethyl } \\
\text { oleate } \\
(10 \\
\%)\end{array}$ & $\underset{(\mathrm{mg} / \mathrm{ml})}{\mathrm{NAP}}$ & $\underset{(\mathrm{mg} / \mathrm{ml})}{\mathrm{IBU}}$ \\
\hline $\mathrm{C}_{\mathrm{NS}}-1$ & & 0.1 & & $x$ & & & \\
\hline $\mathrm{C}_{\mathrm{N}} \mathrm{S}-2$ & & 0.5 & & $x$ & & & \\
\hline $\mathrm{C}_{\mathrm{N}} \mathrm{S}-3$ & & 1 & & $x$ & & & \\
\hline $\mathrm{C}_{\mathrm{NS}}-4$ & & 1.25 & & $x$ & & & \\
\hline $\mathrm{C}_{\mathrm{NS}}-5$ & & 1.5 & & $x$ & & & \\
\hline $\mathrm{C}_{\mathrm{NE}} \mathrm{E}-1$ & & 0.1 & & & $x$ & & \\
\hline $\mathrm{C}_{\mathrm{N}} \mathrm{E}-2$ & & 0.5 & & & $x$ & & \\
\hline $\mathrm{C}_{\mathrm{NE}}-3$ & & 1 & & & $x$ & & \\
\hline $\mathrm{C}_{\mathrm{N}} \mathrm{E}-4$ & & 1.25 & & & $x$ & & \\
\hline $\mathrm{C}_{\mathrm{N}} \mathrm{E}-5$ & & 1.5 & & & $x$ & & \\
\hline HS-1 & 0.1 & & & $x$ & & & \\
\hline HS-2 & 0.5 & & & $x$ & & & \\
\hline HS-3 & 1 & & & $x$ & & & \\
\hline HS-4 & 1.25 & & & $x$ & & & \\
\hline $\mathrm{HS}-5$ & 1.5 & & & $\times$ & & & \\
\hline $\mathrm{HC} \mathrm{NS}_{\mathrm{N}}-1$ & 1 & 0.5 & & $\bar{x}$ & & & \\
\hline $\mathrm{HC}_{\mathrm{NS}} \mathrm{-2}$ & 1 & 1 & & $x$ & & & \\
\hline $\mathrm{HC}_{\mathrm{NS}} \mathrm{S} 3$ & 1 & 1.5 & & $x$ & & & \\
\hline $\mathrm{HC}_{\mathrm{N}} \mathrm{E}-1$ & 1 & 0.5 & & & $x$ & & \\
\hline $\mathrm{HC}_{\mathrm{N}} \mathrm{E}-2$ & 1 & 1 & & & $x$ & & \\
\hline $\mathrm{HC}_{\mathrm{N}} \mathrm{E}-3$ & 1 & 1.5 & & & $x$ & & \\
\hline $\mathrm{HCoS}-1$ & 1 & & 0.5 & $x$ & & & \\
\hline $\mathrm{HCoS}-2$ & 1 & & 1 & $x$ & & & \\
\hline $\mathrm{HCoS}-3$ & 1 & & 1.5 & $x$ & & & \\
\hline $\mathrm{HCoE}-1$ & 1 & & 0.5 & & $x$ & & \\
\hline $\mathrm{HCoE}-2$ & 1 & & 1 & & $x$ & & \\
\hline $\mathrm{HCoE}-3$ & 1 & & 1.5 & & $x$ & & \\
\hline NAP-1 & 1 & 1 & & $x$ & & 0.1 & \\
\hline NAP-2 & 1 & & 1 & $x$ & & 0.1 & \\
\hline NAP-3 & 1 & 1.5 & & $x$ & & 0.1 & \\
\hline NAP-4 & 1 & & 1.5 & $x$ & & 0.1 & \\
\hline NAP-5 & 1 & & & $x$ & & 0.1 & \\
\hline $\begin{array}{l}\text { IBU-1 } \\
\end{array}$ & 1 & 1 & & $x$ & & & 0.1 \\
\hline IBU-2 & 1 & & 1 & $x$ & & & 0.1 \\
\hline IBU-3 & 1 & 1.5 & & $x$ & & & 0.1 \\
\hline IBU-4 & 1 & & 1.5 & $x$ & & & 0.1 \\
\hline IBU-5 & 1 & & & $x$ & & & 0.1 \\
\hline $\begin{aligned} \mathbf{H}= & \text { HFBII } \\
\mathbf{C}_{\mathrm{N}}= & \text { NFC-N (native } \\
\mathbf{C}_{\mathrm{O}}= & \text { NFC-O (TEMP } \\
\mathbf{S}= & \text { soybean oil } \\
\mathbf{E}= & \text { ethyl oleate } \\
\text { IBU }= & \text { ibuprofen form } \\
\mathrm{NAP}= & \text { naproxen form }\end{aligned}$ & $\begin{array}{l}\text { anofibrillated } \\
\text { oxidized nan } \\
\text { ation } \\
\text { ation }\end{array}$ & $\begin{array}{l}\text { llulose) } \\
\text { ibrillated cell }\end{array}$ & & & & & \\
\hline
\end{tabular}




\subsubsection{Emulsion droplet size and zeta-potential measurements}

HFBII stabilized emulsions were diluted $1: 10$ with dilute HFBII $(0.01 \mathrm{mg} / \mathrm{ml}$ in ultrapure water) solution to avoid the possible breakage of HFBII protein coated emulsion droplet $\mathrm{o} / \mathrm{w}$ interface surface structures. The zeta-potential values of emulsion droplets were measured by a ZetaSizer Nano-ZS (Malvern Ltd., UK) in water at $25^{\circ} \mathrm{C}$ in a folded capillary cell (Malvern Ltd., UK). Dynamic light scattering (DLS) measurements for hydrodynamic diameter and size distribution of emulsion droplets were also measured by a ZetaSizer Nano-ZS (Malvern Ltd., UK) in water at $25^{\circ} \mathrm{C}$ in disposable polystyrene cuvettes (Sarstedt,Germany). Size measurements were performed at day 1 and at day 28 after the emulsion preparation, whereas zeta-potential measurements were performed only at day 1 .

\subsubsection{Emulsion stability index (ESI)}

The stability of the emulsions was evaluated by following the emulsion phase separation. Qualitative emulsion stability index (ESI) values were used to evaluate the phase separation of emulsions during 1 month storage at $4^{\circ} \mathrm{C}$ in glass vials (Varjonen et al., 2011). Digital camera images were taken to follow the phase separation of clear aqueous phase from the opaque emulsion phase. The volume fraction of opaque emulsion phase was determined from the separation of the clear aqueous phase. The digital camera images were analyzed with ImageJ software (National Institutes of Health, Bethesda, USA). With ImageJ, a line was drawn from the top to the bottom of the emulsion in the glass vial. Maximum and minimum intensities along the line length that represented the total volume were determined in order to estimate emulsion separation. The distance values in pixels ( $\mathrm{x}$-axis) were plotted against gray values (y-axis). The distance values were normalized to represent the total emulsion volume (x-axis). The gray values were normalized to represent emulsion/water separation (y-axis). Above or at a value of 0.5 (at a scale of 0-1) at y-axis, the corresponding volume fraction at $\mathrm{x}$-axis was considered to be unseparated opaque emulsion. Below the value of 0.5 at $\mathrm{y}$-axis, the corresponding volume fraction at $\mathrm{x}$-axis was considered to be separated clear aqueous phase. ESI values were calculated from the volume of separated water and total volume as follows.

$$
E S I=1-\frac{V_{w, \text { separated }}}{V_{\text {total }}}
$$

ESI value 1 corresponds to completely unseparated emulsion whereas 0 is a value for completely separated system. The ESI values were calculated at day 1, 3, 7, 14, 21 and 28 after the emulsion preparation.

\subsubsection{Viscosity measurements}


1 The shear rate viscosity of ultrapure water, $0.1 \%$ and $0.15 \%$ NFC-N and NFC-O was measured at

$2 \quad 4^{\circ} \mathrm{C}$ with HAAKE Viscotester iQ Rheometer (Thermo Fisher Scientific, Karlsruhe, Germany)

3 equipped with a Peltier system for temperature control. Results were analyzed with HAAKE

RheoWin 4.0 software (Thermo Fisher Scientific). Cup and double-gap cylinder geometry was used with a $4.0 \mathrm{~mm}$ gap and $2.64 \mathrm{ml}$ sample volume. Before each measurement, the samples were allowed to rest for $2 \mathrm{~min}$ at $4^{\circ} \mathrm{C}$. Shear viscosity was measured by increasing the shear rate from 100 to 1900 $1 / \mathrm{s}$. All measurements were performed in triplicate.

\subsubsection{Screening of oils for emulsions}

The solubility of NAP and IBU in soybean oil and ethyl oleate was measured. An excess amount of NAP and IBU were added to both oils, and then mixed with magnetic stirring. After stirring for $72 \mathrm{~h}$ at $25^{\circ} \mathrm{C}$, the equilibrated samples were centrifuged for $10 \mathrm{~min}$ at $14000 \mathrm{~g}$ to remove excess amount of undissolved drug. Then the supernatant was filtered through a $0.2 \mu \mathrm{m}$ pore size Minisart syringe filter, Sartorius, Germany. Filtered supernatants were diluted first with methanol/acetonitrile (50:50) and then further with acetonitrile/phosphate buffer $\mathrm{pH} 2$ (40/60). The concentrations of NAP and IBU were determined with Ultra performance liquid chromatography (UPLC) instrument Acquity UPLC (Waters, USA).

\subsubsection{Cryo-TEM and light microscopy}

Optical microscopy images of emulsions were taken with an optical microscope (Leica DMLB, Germany) and a microscope coupled digital camera as a quality control. Emulsion samples were diluted 1:10 for light microscopy imaging. A single droplet of an emulsion was dropped between the object plate and the cover glass for optical imaging. Emulsions were further imaged and characterized with 200 kV Tecnai F20 Cryo-TEM microscope (FEI Company, Holland). Before freezing, the 300 mesh copper grids (Quantifoil R2/2, Holey Carbon Film) were treated with glow discharge treatment. The samples were frozen as thin films with automatic plunge freezing and bare grid technique (Leica EM GP, Germany) using liquid nitrogen cooled ethane.

\subsubsection{In vitro drug release studies}

In vitro drug release studies were performed in side-by-side-diffusion cells (Laborexin, Finland). Whatman $0.4 \mu \mathrm{m}$ pore size Nuclepore Track-Etch polycarbonate membrane filters were clamped between two identical halves of diffusion cells. The exposed surface area of the clamped membrane was $0.785 \mathrm{~cm}^{2}$. The diffusion cells were kept at $37^{\circ} \mathrm{C}$ by a surrounding water socket to mimic physiological conditions. $0.8 \mathrm{ml}$ of drug containing emulsion $(0.1 \mathrm{mg} / \mathrm{ml}$ of drug) was transferred into the donor compartment, which was filled to $3.5 \mathrm{ml}$ final volume with $0.1 \mathrm{M}$ phosphate buffer $\mathrm{pH}$ 
7.4. The acceptor compartment was filled with $3.5 \mathrm{ml}$ of $0.1 \mathrm{M} \mathrm{pH} 7.4$ phosphate buffer. Free drug solutions of NAP and IBU were used as drug release controls through the membrane. The control samples in the donor compartment contained $0.08 \mathrm{mg}$ of drug per $3.5 \mathrm{ml}$ volume corresponding to $100 \%$ of drug in the emulsions. $200 \mu \mathrm{l}$ samples were collected from the acceptor compartment and replaced with $200 \mu \mathrm{l}$ of fresh buffer at $0.17,0.5,1,2,3,4,5,6,7$ and $8 \mathrm{~h}$. The free drug solutions of NAP and IBU were used as controls.

NAP and IBU concentrations from the in vitro drug release samples were analyzed with Ultra performance liquid chromatography (UPLC) instrument Acquity UPLC (Waters, USA). For NAP, the column was a BEH Shield column $1.7 \mu \mathrm{m}(2.1 \times 50 \mathrm{~mm})$ (Waters, USA) at $30^{\circ} \mathrm{C}$. The flow rate was $0.5 \mathrm{ml} / \mathrm{min}$ and the injection volume $5 \mu \mathrm{l}$. The detection was performed at a wavelength of 231 $\mathrm{nm}$. During the gradient run, the mobile phase consisted of a mixture of acetonitrile and $15 \mathrm{mM}$ phosphate buffer $\mathrm{pH} 2$ in 30:70 ratio at $0-3 \mathrm{~min}$. After $3 \mathrm{~min}$, the mobile phase ratio was changed to 70:30. The retention time of NAP was $1.49 \mathrm{~min}$. The linear concentration of NAP was established in the range of $0.1-10 \mu \mathrm{g} / \mathrm{ml}$ and LOQ for NAPwas $0.007 \mu \mathrm{g} / \mathrm{ml}$. For IBU the column was a HSS-C18 column $1.8 \mu \mathrm{m}(2.1 \times 50 \mathrm{~mm})$ (Waters, USA) at $30^{\circ} \mathrm{C}$. The flow rate was $0.5 \mathrm{ml} / \mathrm{min}$ and the injection volume $5 \mu \mathrm{l}$. The detection was performed at a wavelength of $219 \mathrm{~nm}$. During the isocratic run the mobile phase consisted of a mixture of acetonitrile and $15 \mathrm{mM}$ phosphate buffer $\mathrm{pH} 2$ in 60:40 ratio. The retention time of IBU was $0.85 \mathrm{~min}$. The linear concentration of IBU was established in the range of $0.1-25 \mu \mathrm{g} / \mathrm{ml}$ and LOQ for IBU was $0.09 \mu \mathrm{g} / \mathrm{ml}$.

\section{Results and discussion}

\subsection{Emulsion droplet size and zeta-potential measurements}

Measurements of emulsion droplet diameters and zeta potential values were performed in order to estimate the minimum amount of the protein needed to gain stable emulsion droplets with the sonication method (Varjonen et al., 2011). Sonication produces emulsions with ultrasound-driven mechanical vibrations. Droplet size, polydispersity index (PDI) and zeta potential measurements were performed for HFBII stabilized and $10 \%$ soybean oil containing preliminary formulations. These HS1 to HS-5 formulations contained $0.1-1.5 \mathrm{mg} / \mathrm{ml}$ of HFBII as the sole emulsion stabilizer (see Table 1). DLS measurements were not possible with the samples containing NFC as the light scattering by the long fibers distorted the signal too much.

Higher HFBII concentrations in the aqueous phase reduced the emulsion droplet sizes effectively from $2013 \mathrm{~nm}$ to $345 \mathrm{~nm}$ and increased the zeta potential values from $25 \mathrm{mV}$ to $32.7 \mathrm{mV}$ (Table 2). Based on DLS and zeta potential measurements it was concluded that HFBII concentrations between 
$1-1.5 \mathrm{mg} / \mathrm{ml}$ (HS-3-HS-5), in the aqueous phase of the emulsions, resulted in good colloidal stability

2 at day 1 . These formulations had smaller droplet sizes and higher zeta potential values over $30 \mathrm{mV}$ when compared to the formulations with smaller amounts of HFBII. However, the PDI values were quite high for all formulations indicating that the size distribution of droplets was wide in all emulsions. It might be possible to obtain monodisperse emulsion droplets with other techniques like homogenization (Maa and Hsu, 1999). At day 28 the emulsion droplet size had increased significantly for formulations with low amount of HFBII $(0.1-0.5 \mathrm{mg} / \mathrm{ml})$ when compared to day 1 results. The amount of HFBII in these emulsions was therefore insufficient. For formulations that contained higher amounts of HFBII $(1-1.5 \mathrm{mg} / \mathrm{ml})$ a decrease in the droplet size at day 28 was observed. This might have been caused by the loss of excess amount of protein at the o/w interface. As HFBII is known to self-associate and form tetramers in an aqueous solution at the concentration range 0.5-10 $\mathrm{mg} / \mathrm{ml}$ (Kisko et al., 2008).

Table 2. DLS and zeta potential measurements at day 1 and 28 after the preparation (mean \pm S.D., $\mathrm{n}=3$ ). Preliminary formulations HS-1 to HS-5 contained $0.1-1.5 \mathrm{mg} / \mathrm{ml}$ of HFBII as the sole emulsion stabilizer. Higher HFBII concentrations reduced the emulsion droplet sizes and increased the zeta potential values. PDI values were relatively high for all formulations indicating polydispersity. Abbreviations: $\mathrm{H}=\mathrm{HFBII}$ and $\mathrm{S}=$ soybean oil.

\begin{tabular}{c|c|c|c|c|c} 
Formulation & $\begin{array}{c}\text { Day 1: } \\
\text { z-average } \\
\text { diameter (nm) }\end{array}$ & $\begin{array}{c}\text { Day 28: } \\
\text { z-average } \\
\text { diameter (nm) }\end{array}$ & $\begin{array}{c}\text { Day 1: } \\
\text { PDI }\end{array}$ & $\begin{array}{c}\text { Day 28: } \\
\text { PDI }\end{array}$ & $\begin{array}{c}\text { Day 1: } \\
\text { Zeta Potential (mV) }\end{array}$ \\
\hline HS-1 & $2013 \pm 33$ & $4623 \pm 1879$ & $0.517 \pm 0.014$ & $1 \pm 0$ & $25 \pm 0.6$ \\
\hline HS-2 & $537.6 \pm 11.7$ & $696.8 \pm 208.4$ & $0.415 \pm 0.028$ & $0.492 \pm 0.219$ & $24.8 \pm 0.2$ \\
\hline HS-3 & $339.0 \pm 1.6$ & $324.9 \pm 39.0$ & $0.440 \pm 0.012$ & $0.349 \pm 0.035$ & $31.4 \pm 1.0$ \\
\hline HS-4 & $301.4 \pm 7.3$ & $194.1 \pm 0.9$ & $0.443 \pm 0.024$ & $0.144 \pm 0.027$ & $30.2 \pm 1.0$ \\
\hline HS-5 & $345.0 \pm 4.7$ & $183.6 \pm 1.3$ & $0.520 \pm 0.017$ & $0.129 \pm 0.006$ & $32.7 \pm 1.1$ \\
\hline
\end{tabular}

HS-3 formulation contained $1 \mathrm{mg} / \mathrm{ml}$ of HFBII and the emulsion droplet size did not change drastically during 28 days. Therefore, $1 \mathrm{mg} / \mathrm{ml} \mathrm{HFBII} \mathrm{concentration} \mathrm{was} \mathrm{selected} \mathrm{to} \mathrm{be} \mathrm{used} \mathrm{in} \mathrm{the}$ combination formulations with NFC fibers. HFBII has been shown to adsorb to hydrophobic interfaces, such as hydrophobic polymer films and o/w interphase of an emulsion, and to lower the interfacial tension even at low concentrations (Lumsdon et al., 2005). $0.2 \mathrm{mg} / \mathrm{ml}$ HFBII concentration in the aqueous phase has been shown to stabilize o/w emulsions effectively. These results support our finding that HFBII can be used as a surfactant to stabilize emulsions at extremely low concentrations. Furthermore HFBs are nontoxic, which is an advantage when HFBs are used as pharmaceutical excipients (Aimanianda et al., 2009;Ebbole, 1997). 
1 The sonication method produced submicron emulsion droplets with high zeta potential values (Table 2). Therefore, the emulsion quality was considered to be sufficient for the evaluation of HFBII and NFC materials in the stabilization of pharmaceutical emulsions. Different sonication times and highshear mixing were tested with HS-3 formulation in order to evaluate further whether the emulsion droplet size and PDI values could be decreased. Based on the results it was observed that a sonication time of 2 minutes was optimal (Table 3). Longer sonication times or high-shear mixing resulted in over processing and significant increase in the droplet size. The size range of droplet diameters was in micrometers with high-shear mixing as opposed to nanometers obtained with sonication. Therefore, high-shear mixing was not suitable as a preparation process. Furthermore, it was observed that it was beneficial to mix all formulation components gently by repeated pipetting prior to sonication while preparing the formulations that contained NFC in addition to HFBII. The addition of NFC after the sonication of HFBII and other formulation components (oil and water) was tested, but this approach led to fast phase separation in a matter of minutes.

Table 3. The effect of the preparation process on emulsion droplet size and PDI values (mean \pm S.D., $\mathrm{n}=3$ ). HS-3-formulation was prepared with sonication and high-shear mixing techniques with different mixing durations. Sonication technique produced overall smaller emulsion droplet diameters than the high-shear mixing technique.

\begin{tabular}{c|c|c|c|c} 
Preparation method & $\begin{array}{c}\text { Day 1: } \\
\text { z-average } \\
\text { diameter }(\mathbf{n m})\end{array}$ & $\begin{array}{c}\text { Day 28: } \\
\text { z-average } \\
\text { diameter } \mathbf{( n m})\end{array}$ & $\begin{array}{c}\text { Day 1: } \\
\text { PDI }\end{array}$ & $\begin{array}{c}\text { Day 28: } \\
\text { PDI }\end{array}$ \\
\hline 2 min sonication & $339.0 \pm 1.6$ & $324.9 \pm 39.0$ & $0.440 \pm 0.012$ & $0.349 \pm 0.035$ \\
\hline 3 min sonication & $415.3 \pm 6.1$ & $366.0 \pm 6.2$ & $0.796 \pm 0.046$ & $0.310 \pm 0.008$ \\
\hline 4 min sonication & $550.0 \pm 18.7$ & $480.0 \pm 11.8$ & $0.937 \pm 0.045$ & $0.540 \pm 0.027$ \\
\hline 5 min sonication & $605.9 \pm 55.3$ & $357.0 \pm 35.0$ & $0.834 \pm 0.113$ & $0.550 \pm 0.090$ \\
\hline 1 min high-shear mixing & $4117 \pm 468$ & $\mathrm{nd}$ & $0.319 \pm 0.052$ & $\mathrm{nd}$ \\
\hline 2 min high-shear mixing & $4327 \pm 202$ & $\mathrm{nd}$ & $0.372 \pm 0.073$ & $\mathrm{nd}$ \\
\hline 4 min high-shear mixing & $6388 \pm 120$ & $\mathrm{nd}$ & $0.123+0.029$ & $\mathrm{nd}$ \\
\hline
\end{tabular}

\subsection{NFC and HFBII as emulsion stabilizers}

\subsubsection{Formulations and emulsion stability index (ESI)}

Formulation optimization process was performed by evaluating the ability of different formulation components and their combinations to stabilize the emulsion. Emulsions of soybean oil or ethyl oleate and water in the presence of HFBII $(1 \mathrm{mg} / \mathrm{ml})$ and/or NFC were studied (see Table 1 for details). Soybean oil and ethyl oleate are pharmaceutically acceptable oils that have been used successfully in a variety of pharmaceutical formulations (Chen et al., 2006; Cui et al., 2009; Gorain et al., 2014;Wulff- 
1 oral and topical formulations. The stability of different formulations were evaluated by following the 2 phase separation of emulsions with ESI (Fig. 1A-F). The best material combinations were selected 3 for IBU and NAP formulations based on the highest ESI values of preliminary formulations.

4 The ability of NFC-N $(0.1-1.5 \mathrm{mg} / \mathrm{ml})$ to stabilize the emulsions increased when a higher amount of

5 NFC-N was used in combination with soybean oil (Fig. 1A-B). NFC-N formulations with soybean 6 oil were more stable than with ethyl oleate during the 28 day period, which could be observed as 7 higher ESI values and less phase separation. The stability of the soybean oil based emulsions 8 increased in direct proportion to the amount of NFC-N, whereas the effect of NFC-N amount on the 9 stability of ethyl oleate emulsions could not be seen as clearly. It has been previously shown that a 10 continuous NFC-N matrix forms in the aqueous phase of o/w emulsions when NFC-N concentration 11 is increased to $1 \mathrm{mg} / \mathrm{ml}$ (Varjonen et al., 2011). This was reportedly followed by association of oil 12 droplets to the NFC-N fibrils most likely caused by the emulsification process. Best stability was 13 gained in our study when at least $1.5 \mathrm{mg} / \mathrm{ml}$ NFC-N was used with soybean oil in emulsion 14 stabilization. Reportedly the addition of NFC increases the viscosity of the continuous phase of o/w 15 emulsions and creates a polymer network that limits drop collision, thus reducing the coalescence 16 phenomena (Carrillo et al., 2015;Dimic-Misic et al., 2013;Garti, 1999; Xhanari et al., 2011). 17 Therefore, the stability of NFC-N containing emulsions depended on the concentration of NFC-N 18 due to the increased viscosity of the water phase as well as the benefits gained from increasing the 19 amount of NFC for encapsulation of the oil droplets. 

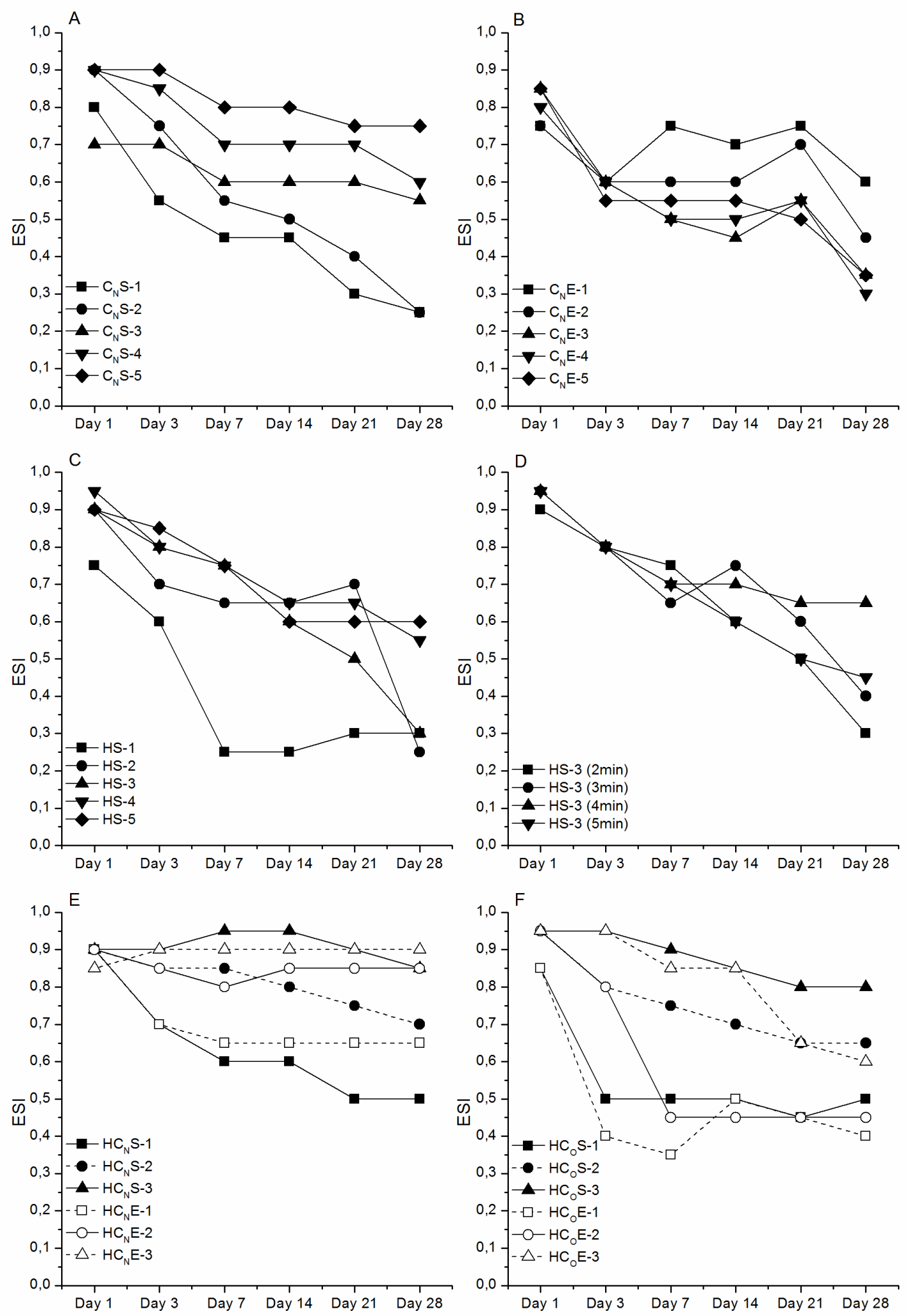

Figure 1. Emulsion stability index (ESI) values for different emulsion formulations $(n=1)$ : A) NFC$\mathrm{N}$ with soybean oil, B) NFC-N with ethyl oleate, C) HFBII with soybean oil, D) $1 \mathrm{mg} / \mathrm{ml} \mathrm{HFBII} \mathrm{(HS-}$ 3) with soybean oil prepared by different sonication times, E) HFBII-NFC-N formulations with soybean oil or ethyl oleate, F) HFBII-NFC-O formulations with soybean oil or ethyl oleate. Abbreviations: $\mathrm{H}=\mathrm{HFBII}, \mathrm{C}_{\mathrm{N}}=\mathrm{NFC}-\mathrm{N}$ (native nanofibrillated cellulose), $\mathrm{C}_{\mathrm{O}}=\mathrm{NFC}-\mathrm{O}$ (TEMPO oxidized nanofibrillated cellulose), $\mathrm{S}=$ soybean oil and $\mathrm{E}=\mathrm{ethyl}$ oleate. 
1 When HFBII $(0.1-1.5 \mathrm{mg} / \mathrm{ml})$ was used for emulsion stabilization only the formulation that contained the smallest amount of HFBII $(0.1 \mathrm{mg} / \mathrm{ml})$ was clearly unstable (Fig. 1C). The most stable formulations contained $1.25-1.5 \mathrm{mg} / \mathrm{ml}$ of HFBII, which indicated clearly that the stability of these emulsions increased in direct proportion to HFBII content. However, $1 \mathrm{mg} / \mathrm{ml}$ HFBII concentration (HS-3 formulation) was selected to be used in combination with NFC due to the size and PDI measurements that clearly indicated 1.25 and $1.5 \mathrm{mg} / \mathrm{ml}$ concentrations to be excessive (Table 2). The stability of $1 \mathrm{mg} / \mathrm{ml}$ HFBII stabilized HS-3 formulation series that was prepared with different sonication times was tested (Fig. 1D). Differences in emulsion stability evaluated by phase separation were quite small. By contrast, the emulsion droplet size and PDI value increased when sonication time was increased. Regarding the overall emulsion stability 2 min sonication time was optimal.

The stability of the emulsions was increased when adequate amounts of HFBII and NFC-N or NFC$\mathrm{O}$ were used in combination (Fig. 1E-F). The ESI values were higher than when sole emulsion stabilizers were used in the formulations. We tested $0.5,1$ and $1.5 \mathrm{mg} / \mathrm{ml}$ concentrations of NFC-N and NFC-O in combination with $1 \mathrm{mg} / \mathrm{ml} \mathrm{HFBII}$ and evaluated the impact of the two oils, soybean oil and ethyl oleate, on ESI values. Formulations with low amounts $(0.5 \mathrm{mg} / \mathrm{ml})$ of NFC-N or NFC$\mathrm{O}$ proved to be quite unstable as the emulsion phase separation was quite fast already at day 3 . The most stable formulations had $1.5 \mathrm{mg} / \mathrm{ml}$ of NFC-N or NFC-O in combination with $1 \mathrm{mg} / \mathrm{ml}$ of HFBII. Relatively stable emulsions were obtained when the surfactants like properties of HFBII were combined with NFC that can be used to modify the viscosity of the water phase in addition to droplet encapsulation. Based on the emulsion stability data, the HFBII concentration was kept at a constant $1 \mathrm{mg} / \mathrm{ml}$ and two different NFC-N and NFC-O concentrations, $1 \mathrm{mg} / \mathrm{ml}$ and $1.5 \mathrm{mg} / \mathrm{ml}$, were selected for the drug containing formulations in the release studies.

Shear viscosities of $1 \mathrm{mg} / \mathrm{ml}(0.1 \%)$ and $1.5 \mathrm{mg} / \mathrm{ml}(0.15 \%)$ of NFC-N and NFC-O were measured as a function of shear rate in order to evaluate the effect of NFC concentration on the viscosity of aqueous continuous phase in emulsions (Fig. 2). NFC-N at low concentrations of $0.1 \%$ and $0.15 \%$ did not affect the viscosity significantly as the shear rate did not affect the viscosity and the viscosity profile was similar to pure water. NFC-O had approximately ten times higher viscosity values than NFC-N at $100(1 / s)$ shear rate. Furthermore, moderate shear thinning was observed for NFC-O. It has been shown for both NFC grades in several previous studies that the concentration affects the viscosity and intense shear thinning behavior is observed (Benhamou et al., 2014;Bhattacharya et al., 2012;Nechyporchuk et al., 2014;Pääkkö et al., 2007). NFC hydrogels can be classified as pseudoplastic materials in this regard. 




2 Figure 2. Shear rate viscosities of water, $0.1 \%$ and $0.15 \%$ of NFC-N and NFC-O at $4{ }^{\circ} \mathrm{C}(\mathrm{mean} \pm$ 3 S.D., $n=3$ ).

4 The low shear viscosity of $0.1 \%$ and $0.15 \%$ NFC-N and NFC-O was not surprising as there was a 5 very small amount of fibers to form the NFC network in the aqueous environment. Upon exposing increased shear rate the weakly bonded network falls apart easily and individual fibers start to flow. However, as NFC-O had slightly higher shear viscosity at $4{ }^{\circ} \mathrm{C}$, which was also used as the storage temperature of emulsions, it seems that NFC-O may be more effective in emulsion stabilization due to modified viscosity of the continuous phase even at low concentrations. The effect of low NFC-N concentration on viscosity was minimal. The emulsion stabilizing effect of NFC-N at $0.1-0.15 \%$ concentration may be attributed to the reduced emulsion droplet movement rather that the increased viscosity of the continuous phase.

The solubility of NAP and IBU in soybean oil and ethyl oleate was measured to find the drug solubilization capacity of the oils (Table 4). Ethyl oleate had a higher solubilization capacity than soybean oil with regard to both drugs. The solubility of NAP was $2.8 \mathrm{~g} / \mathrm{L}$ in soybean oil and $5.1 \mathrm{~g} / \mathrm{L}$ in ethyl oleate. For IBU, the solubility was $46.2 \mathrm{~g} / \mathrm{L}$ in soybean oil and $98.7 \mathrm{~g} / \mathrm{L}$ in ethyl oleate. The different drug solubilization capacity of soybean oil and ethyl oleate is attributed to the structural differences of these oils (Chen et al., 2006;Date and Nagarsenker, 2008;Sharif Makhmalzadeh et al., 2012). Vegetable origin soybean oil contains triglycerides with long hydrocarbon chains and is a high molecular volume oil, whereas fatty acid ester ethyl oleate is a lower molecular volume oil than soybean oil (Date and Nagarsenker, 2008). Soybean oil with a $1563 \AA^{3}$ molecular volume has been shown to have a slightly lower solubilizing capacity for lipophilic drugs than ethyl oleate with a 600 $\AA^{3}$ molecular volume (Malcolmson et al., 1998). However, the solubility of both drugs in tested oils was significantly higher than the aqueous solubility. Therefore, the emulsion formulations containing either of these oils can be used to effectively solubilize both NAP and IBU. Soybean oil was selected for the oil phase in the emulsions and for the solubilization of poorly water-soluble model drugs NAP 
and IBU as it proved to be slightly better than ethyl oleate with regard to ESI values. $10 \%$ of oil phase

2 and $90 \%$ of aqueous phase with $0.1 \mathrm{mg} / \mathrm{ml}$ drug loading was used for all emulsions. The drug amount

3 in the emulsions can be improved by a higher amount of drug in the oil phase or by a higher amount

4 of the oil phase. However, these conditions were chosen for the release studies in order to evaluate

5 the performance of the emulsion stabilizing excipients. Further studies are needed to optimize the

6 amount of NFC and HFBII for emulsions with a higher volume of oil phase.

7 Table 4. Solubility values for NAP and IBU in aqueous media, soybean oil and ethyl oleate.

\begin{tabular}{c|c|c|c|c|c|c} 
Compound & $\begin{array}{c}\text { Molar mass } \\
(\mathbf{g} / \mathbf{m o l})\end{array}$ & pKa & $\log \mathbf{P}$ & $\begin{array}{c}\text { Solubility in } \\
\text { aqueous media }\end{array}$ & $\begin{array}{c}\text { Solubility in } \\
\text { soybean oil }\end{array}$ & $\begin{array}{c}\text { Solubility in } \\
\text { ethyl oleate }\end{array}$ \\
\hline NAP & 230.3 & 4.15 & 3.18 & $\begin{array}{c}15.9 \mathrm{mg} / \mathrm{L}, \mathrm{MQ}^{\mathrm{a}} \\
2.8-3.6 \mathrm{~g} / \mathrm{L}, \mathrm{pH}=7.4^{\mathrm{b}}\end{array}$ & $2.8 \mathrm{~g} / \mathrm{L}$ & $5.1 \mathrm{~g} / \mathrm{L}$ \\
\hline IBU & 206.3 & 4.85 & 3.97 & $\begin{array}{c}21 \mathrm{mg} / \mathrm{L}, \mathrm{MQ}^{\mathrm{c}} \\
6 \mathrm{~g} / \mathrm{L}, \mathrm{pH}=7.4^{\mathrm{d}, \mathrm{e}}\end{array}$ & $46.2 \mathrm{~g} / \mathrm{L}$ & $98.7 \mathrm{~g} / \mathrm{L}$ \\
\hline
\end{tabular}

8 aYalkowsky et al., 2003; bMora and Martínez, 2006; 'Yalkowsky and Dannenfelser, 1992;

9 dLerdkanchanaporn et al., 2001; eLevis et al., 2003

\subsubsection{Characterization with optical microscopy and cryo-TEM}

HFBII stabilized emulsion droplets could clearly be observed in optical microscopy as well as cryoTEM images. Optical microscopy images of formulations that were selected for the drug release studies were taken after 1:10 dilution as a quality control (Fig. 3 A-C). The formulations contained HFBII and combinations of HFBII-NFC-N and HFBII-NFC-O as stabilizers. NFC-O stabilized emulsions seemed to be more stable upon dilution in light microscopy images than NFC-N stabilized (Fig. 3B-C). NFC-O stabilized emulsions had more uniform distribution of emulsion droplets in evenly distributed fiber network whereas NFC-N stabilized emulsions formed clusters of NFC-N and emulsion droplets upon dilution. Emulsion droplets with diameters in the micrometer range were observed with optical microscopy. 




Figure 3. Light microscopy and cryo-TEM images of HFBII, HFBII-NFC-N (1:1 mass ratio) and HFBII-NFC-O (1:1 mass ratio) stabilized emulsions. Upper image row (A-C) contains light microscopy images of respective formulations, whereas lower image row (D-F) contains cryo-TEM images. The emulsion droplets of HFBII-NFC-N and HFBII-NFC-O formulations were within the entangled NFC fibers. For solely HFBII stabilized emulsions only spherical emulsion droplets were observed. Scale bar is $40 \mu \mathrm{m}$ for A-C, $100 \mathrm{~nm}$ for D-E and $200 \mathrm{~nm}$ for F image.

The spherical morphology of the protein coated emulsion droplets as well as the wide size distribution in all formulations was confirmed with cryo-TEM (Fig. 3D-F). For HFBII-NFC-N formulation the fibrous NFC matrix surrounded the emulsion droplets, whereas for solely HFBII stabilized emulsion only the protein coated spherical emulsion droplets were observed. The NFC-O fibers surrounding the protein coated oil droplets consisted of shorter NFC-O fibers as observed in cryo-TEM images (Fig. 3F) as opposed to the longer NFC-N fibers (Fig. 3E). NFC-O fibers are typically shorter than NFC-N fibers due to the oxidation process that reduces the fiber length (Benhamou et al., 2014). It was observed that the emulsion droplets had a tendency to exist as clusters when stabilized with the shorter NFC-O fibers. The expected stabilization mechanism, a combination of HFBII stabilized oil droplets with NFC fiber network, of the emulsions was confirmed with cryo-TEM.

\subsection{In vitro drug release studies}


1 In vitro drug release studies were done in diffusion cells through a $0.4 \mu \mathrm{m}$ pore size membrane.

2 Therefore, lag times were observed in the release rate profiles at the beginning of the drug release

3 studies. The model compounds NAP and IBU both have three distinctive diffusion steps from the o/w emulsions in our experimental setup that need to be considered when interpreting the drug release results. These steps include: 1) diffusion across the HFBII coated oil droplet interfacial film, 2) diffusion through the water phase of the diluted emulsion in the donor compartment and 3) diffusion from the donor compartment across the membrane to the receptor solution.

The drug release profiles of NAP and IBU from solely HFBII stabilized formulations were compared to NFC containing formulations. The amount and grade of NFC was investigated in terms of effect to drug release rate. The cumulative drug release of NAP and IBU from the HFBII, HFBII-NFC-N and HFBII-NFC-O stabilized emulsions are presented in Figure. 3. NAP (pKa 4.15) and IBU (pKa 4.85) are both weak acids and poorly soluble in low $\mathrm{pH}$ values but have a high solubility above $\mathrm{pH}$ 6.8 due to the ionization (Álvarez et al., 2011;Khadra et al., 2015). Therefore, the diffusion of NAP and IBU across the HFBII coated oil droplet interfacial films and NFC fiber matrix was evaluated by using the free drug solutions of NAP and IBU as positive controls for immediate release. The in vitro drug release experiments, conducted under sink conditions, indicated that different formulation compositions had an impact on the drug release rate when compared to the free drug solution controls of NAP and IBU. Major differences in the drug release rate were observed depending on the grade of NFC fibers used in the formulations.

NAP release was fast from HFBII-NFC-N formulations and 64-70\% was released during $8 \mathrm{~h}$ in comparison to $85 \%$ of the free drug through the membrane (Fig. 4). The drug release was slightly slower than for the positive control of immediate release (free drug solution), but still close to an immediate drug release profile. Sustained drug release profile for NAP was obtained with the HFBIINFC-O formulations as only 18-27\% was released during $8 \mathrm{~h}$. The drug release of NAP from HFBII formulation (NAP-5) resembled a sustained release profile with the $38 \%$ of drug release during $8 \mathrm{~h}$. The amount of NFC-N or NFC-O in the formulation affected only slightly the drug release rates of NAP. However, the grade of NFC fibers used in the formulations with HFBII had a significant impact. 

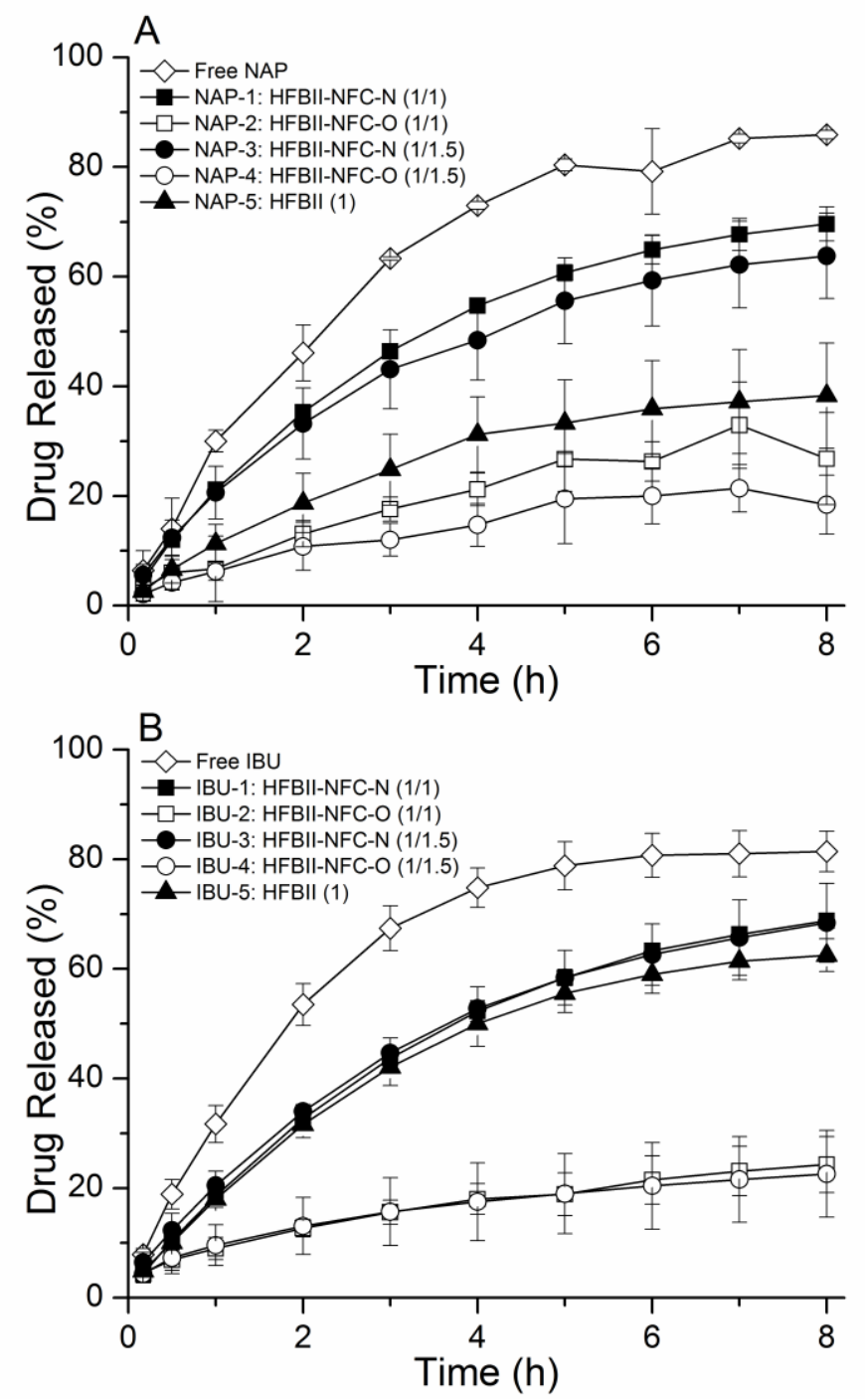

Figure 4. Drug release studies with NAP andIBU: A) Cumulative NAP release (\%) from different formulations (mean \pm S.D., $n=3-5$ ), B) Cumulative IBUrelease from different formulations (mean \pm S.D., $\mathrm{n}=4-5)$. Mass ratios of HFBII to NFC-N or NFC-O are in brackets.

The drug release results of NAP and IBU from different formulations were rather similar (Fig. 4). IBU release was fast from the HFBII-NFC-N and HFBII formulations. 62-67\% of IBU was released in $8 \mathrm{~h}$, while $80 \%$ of the free drug had passed through the membrane in the same time. Sustained drug release profiles were obtained for IBU with HFBII-NFC-O formulations as only 20-23\% of IBU was released during $8 \mathrm{~h}$. The amount of NFC-N or NFC-O in the formulation did not affect significantly the IBU release rates, but the grade of NFC fibers did. Overall, the model drugs were released in a sustained manner from the HFBII-NFC-O formulations. By comparison, immediate release profiles were gained with the HFBII-NFC-N formulations. It was expected that different release profiles would be gained with these materials as it has been previously reported that the drug interactions with 
1 HFBII and different NFC-grades has an impact on the drug release rate (Kolakovic et al., 2013;Valo

et al., 2010; Valo et al., 2013). Especially pH dependent electrostatic interactions between drug molecules and NFC fibers seem to play an important role with regard to drug release (Kolakovic et al., 2013). It is possible that some drug interactions existed with both NFC grades driven by aromatic $\pi$ stacking and hydrogen bonding. However, physical interactions such as viscosity, stability and the surface barrier of the emulsion droplets were most likely more critical in determining the drug release rates.

At $\mathrm{pH} 7.4$ both NFC grades are negatively charged, but NFC-O has a greater negative charge due to a greater distribution of carboxyl groups directly at the fiber surface (Saito et al., 2007; Weishaupt et al., 2015). HFBII has an isoelectric point (pI) of 6.7 and a negative net charge at higher $\mathrm{pH}$ values (Krivosheeva et al., 2013). However, it is possible that the protein coated oil droplets may have had a positive charge at $\mathrm{pH} 7.4$ as the formation of tight interfacial HFBII film reportedly reduces the surface area and ionizable functional groups exposed to water resulting in a shift of the pI (Basheva et al., 2011). The measured zeta potential values of HFBII stabilized preliminary formulations indicated positive net charge at neutral environment of ultrapure water (Table 2). It is likely that the sustained release profiles of NAP and IBU from HFBII-NFC-O formulations were attributed to a greater diffusion barrier at the $\mathrm{o} / \mathrm{w}$-interphase that was present due to electrostatic attraction between negatively charged NFC-O and positively charged HFBII. As NFC-N has a lower negative charge, the effect was not as pronounced resulting in an immediate drug release profiles.

Futhermore, NFC-O stabilized emulsions were more stable upon dilution (Fig. 3B-C, 10x dilution) and the emulsion structure remained more intact than with NFC-N. This was probably attributed the high surface density of negative charges of NFC-O fibers due to multiple carboxyl groups on the fiber surface (Benhamou et al., 2014). Since the emulsions were slightly diluted (4x) in the release experiments, the electrostatic repulsion between NFC-O fibers may have stabilized the emulsion droplets of HFBII-NFC-O formulations more effectively in addition to electrostatic attractive interactions between HFBII and NFC-O. Furthermore, NFC-O had a higher viscosity than NFC-N (Fig.2) indicating that NFC-O was a more effective grade for emulsion storage stabilization due to increased viscosity of the continuous phase. In theory, the higher viscosity of HFBII-NFC-O formulations may have prolonged the drug release, but upon dilution the effect should have been minimal. We believe that the sustained drug release properties of HFBII-NFC-O formulations were at least partially attributed to the electrostatic interactions between HFBII and NFC-O, which stabilized the emulsion structure. 
1 For solely HFBII protein stabilized formulations an immediate and sustained drug release profiles were observed for IBU and NAP respectively. IBU has a higher solubility at $\mathrm{pH} 7.4$ than NAP (see Table 4.). The solubility difference at $\mathrm{pH} 7.4$ may be the reason for the differences in the drug release rates of these molecules. The solubility of the diffusing drug molecules can reportedly have a higher effect on drug release rate than the interfacial film properties of the emulsion droplets (Llinàs et al., 2013). Consequently, the solubility of the ionized drug molecules, in the $\mathrm{pH} 7.4$ release medium, can affect the diffusion rate from the inner oil phase and overall drug release. Therefore, it was concluded that while the HFBII formulations were successful in controlling the drug release to some extent it was beneficial to add NFC into the formulations to gain well defined release profiles. Furthermore, the storage stability of the emulsions was improved when NFC was used in the stabilization together with HFBII (Fig. 1).

HFB proteins have hydrophobic and hydrophilic patches directly at their surfaces (Lumsdon et al., 2005;Paananen et al., 2013;Szilvay et al., 2007). The amphiphilic nature of HFBII has been exploited for hydrophilic and hydrophobic interactions with interfaces. Previously the ability of HFBs to modify hydrophobic interfaces into hydrophilic ones has been used in nanoencapsulation of hydrophobic nutraceuticals, stabilization of emulsions and hydrophobic drug nanoparticles (IsraeliLev and Livney, 2014; Valo et al., 2010; Varjonen et al., 2011). Here HFBII was mainly used to stabilize the $\mathrm{o} / \mathrm{w}$ interphase of pharmaceutical emulsions and to aid in the solubilization of BCS class II drugs in the oil phase of emulsions. Some hydrophobic and hydrophilic interactions between HFBII and the model drugs may have existed, but the effect on drug release profiles was minimal. Similar release profiles were observed from the HFBII and HFBII-NFC-N formulations apart from NAP with HFBII. The release profiles of IBU and NAP were close to an immediate release profiles from HFBIINFC-N. At the low concentrations of $1 \mathrm{mg} / \mathrm{ml}$ for HFBII and $1-1.5 \mathrm{mg} / \mathrm{ml}$ for NFC-N in the formulations, these materials were better suited for emulsion storage stabilization than to provide controlled release. However, immediate release profile after oral administration is beneficial in many pharmaceutical applications such as analgesia.

Based on the in vitro drug release studies, it was clearly shown that the use of native or oxidized NFC as an emulsion stabilizer results in different drug release profiles. Morphology and the stability of the different formulations most likely had an impact on drug release results. Drug release profiles were affected only moderately by the viscosity of the emulsions or by the interactions of the drug molecules with NFC fibers and HFBII proteins. Clearly both NFC grades, native and TEMPO oxidized, can be used as emulsion stabilizers. However, further studies are needed in order to evaluate a concentration range where HFBII may act as a surfactant and provide sustained release from the inner oil phase. 
1 The oxidized NFC grade seems promising excipient for sustained release formulations as an emulsion stabilizer due to its greater extent to modify the drug release rate. The native NFC grade in turn seems more suitable for formulations that benefit from an immediate drug release profile. As an increasing number of drug candidates suffer from poor aqueous solubility, the emulsion formulation is an option for solubilization of lipophilic drugs and enhancement of the adequate absorption from the GIT following oral administration.

\section{Conclusions}

This study has shown that a combination of natural biopolymers HFBII and nanofibrillated cellulose can be used to tailor emulsions for immediate and sustained drug release applications. The low toxicity of these materials is a significant benefit in drug delivery applications via the oral route when compared to synthetic traditional surfactants. The formulations that contained HFBII and oxidized nanofibrillated cellulose proved to be effective in controlling the drug release rate, which indicated the suitability of these materials for controlled drug release applications. Formulations with HFBII and native nanofibrillated cellulose were more suitable for immediate drug release applications. The drug release profiles or our poorly soluble model compounds, naproxen and ibuprofen, could be tuned by the choice of the nanofibrillated cellulose grade.

\section{Acknowledgements}

The financial support from Academy of Finland (Grant no. 264988 and 258114) is gratefully acknowledged. Orion Foundation of the Professor pool, Finland is greatly acknowledged by M.Y. We are thankful to Timo Oksanen, Pharmaceutical Biosciences, Faculty of Pharmacy, University of Helsinki for assisting with the analysis of naproxen and ibuprofen samples by UPLC. We would also like to thank Electron Microscopy Unit, Institute of Biotechnology, University of Helsinki for cryoTEM imaging of the emulsion samples.

\section{References}

Aimanianda, V., Bayry, J., Bozza, S., Kniemeyer, O., Perruccio, K., Elluru, S.R., Clavaud, C., Paris, S., Brakhage, A.A., Kaveri, S.V., 2009. Surface hydrophobin prevents immune recognition of airborne fungal spores. Nature 460, 1117-1121.

Alexandrescu, L., Syverud, K., Gatti, A., Chinga-Carrasco, G., 2013. Cytotoxicity tests of cellulose nanofibril-based structures. Cellulose 20, 1765-1775. 
Álvarez, C., Núñez, I., Torrado, J.J., Gordon, J., Potthast, H., García-Arieta, A., 2011. Investigation on the possibility of biowaivers for ibuprofen. J. Pharm. Sci. 100, 2343-2349.

Basheva, E.S., Kralchevsky, P.A., Christov, N.C., Danov, K.D., Stoyanov, S.D., Blijdenstein, T.B., Kim, H., Pelan, E.G., Lips, A., 2011. Unique properties of bubbles and foam films stabilized by HFBII hydrophobin. Langmuir 27, 2382-2392.

Benhamou, K., Dufresne, A., Magnin, A., Mortha, G., Kaddami, H., 2014. Control of size and viscoelastic properties of nanofibrillated cellulose from palm tree by varying the TEMPO-mediated oxidation time. Carbohydr. Polym. 99, 74-83.

Bhattacharya, M., Malinen, M.M., Lauren, P., Lou, Y., Kuisma, S.W., Kanninen, L., Lille, M., Corlu, A., GuGuen-Guillouzo, C., Ikkala, O., Laukkanen, A., Urtti, A., Yliperttula, M., 2012. Nanofibrillar cellulose hydrogel promotes three-dimensional liver cell culture. J. Controlled Release 164, 291-298.

Binks, B.P., 2002. Particles as surfactants—-similarities and differences. Current Opinion in Colloid \& Interface Science 7, 21-41.

Carrillo, C.A., Nypelö, T.E., Rojas, O.J., 2015. Cellulose nanofibrils for one-step stabilization of multiple emulsions (W/O/W) based on soybean oil. J. Colloid Interface Sci. 445, 166-173.

Chen, H., Chang, X., Du, D., Li, J., Xu, H., Yang, X., 2006. Microemulsion-based hydrogel formulation of ibuprofen for topical delivery. Int. J. Pharm. 315, 52-58.

Cui, J., Yu, B., Zhao, Y., Zhu, W., Li, H., Lou, H., Zhai, G., 2009. Enhancement of oral absorption of curcumin by self-microemulsifying drug delivery systems. Int. J. Pharm. 371, 148-155.

Date, A.A., Nagarsenker, M.S., 2008. Parenteral microemulsions: An overview. Int. J. Pharm. 355, 19-30.

Davis, W.W., Pfeiffer, R.R., Quay, J.F., 1970. Normal and Promoted Gastrointestinal Absorption of Water-Soluble Substances I: Induced Rapidly Reversible Hyperabsorptive State in the Canine Fundic Stomach Pouch. J. Pharm. Sci. 59, 960-963.

Dimic-Misic, K., Gane, P., Paltakari, J., 2013. Micro-and nanofibrillated cellulose as a rheology modifier additive in CMC-containing pigment-coating formulations. Ind Eng Chem Res 52, 1606616083.

Ebbole, D.J., 1997. Hydrophobins and fungal infection of plants and animals. Trends Microbiol. 5, 405-408.

Fahr, A., 2007. Drug delivery strategies for poorly water-soluble drugs. Expert Opin Drug Deliv 4, 403.

Fall, A.B., Lindström, S.B., Sundman, O., Ödberg, L., Wågberg, L., 2011. Colloidal stability of aqueous nanofibrillated cellulose dispersions. Langmuir 27, 11332-11338. 
Gao, Z., Choi, H., Shin, H., Park, K., Lim, S., Hwang, K., Kim, C., 1998. Physicochemical characterization and evaluation of a microemulsion system for oral delivery of cyclosporin A. Int. J. Pharm. 161, 75-86.

Garti, N., 1999. Hydrocolloids as emulsifying agents for oil-in-water emulsions. J. Dispersion Sci. Technol. 20, 327-355.

Gloxhuber, C., 1974. Toxicological properties of surfactants. Arch. Toxicol. 32, 245-269.

Gorain, B., Choudhury, H., Kundu, A., Sarkar, L., Karmakar, S., Jaisankar, P., Pal, T.K., 2014.

Nanoemulsion strategy for olmesartan medoxomil improves oral absorption and extended antihypertensive activity in hypertensive rats. Colloids and Surfaces B: Biointerfaces 115, 286-294.

Hannukainen, K., Suhonen, S., Savolainen, K., Norppa, H., 2012. Genotoxicity of nanofibrillated cellulose in vitro as measured by enzyme comet assay. Toxicol. Lett. 211, S71.

He, W., Tan, Y., Tian, Z., Chen, L., Hu, F., Wu, W., 2011. Food protein-stabilized nanoemulsions as potential delivery systems for poorly water-soluble drugs: preparation, in vitro characterization, and pharmacokinetics in rats. Int J Nanomedicine 6, 521-533.

Hua, K., Carlsson, D.O., Ålander, E., Lindström, T., Strømme, M., Mihranyan, A., Ferraz, N., 2014. Translational study between structure and biological response of nanocellulose from wood and green algae. RSC Advances 4, 2892-2903.

Israeli-Lev, G., Livney, Y.D., 2014. Self-assembly of hydrophobin and its co-assembly with hydrophobic nutraceuticals in aqueous solutions: Towards application as delivery systems. Food Hydrocoll. 35, 28-35.

Khadra, I., Zhou, Z., Dunn, C., Wilson, C.G., Halbert, G., 2015. Statistical investigation of simulated intestinal fluid composition on the equilibrium solubility of biopharmaceutics classification system class II drugs. European Journal of Pharmaceutical Sciences 67, 65-75.

Kisko, K., Szilvay, G.R., Vainio, U., Linder, M.B., Serimaa, R., 2008. Interactions of hydrophobin proteins in solution studied by small-angle X-ray scattering. Biophys. J. 94, 198-206.

Klemm, D., Kramer, F., Moritz, S., Lindström, T., Ankerfors, M., Gray, D., Dorris, A., 2011. Nanocelluloses: A new family of nature-based materials. Angewandte Chemie International Edition 50, 5438-5466.

Kolakovic, R., Laaksonen, T., Peltonen, L., Laukkanen, A., Hirvonen, J., 2012. Spray-dried nanofibrillar cellulose microparticles for sustained drug release. Int. J. Pharm. 430, 47-55.

Kolakovic, R., Peltonen, L., Laukkanen, A., Hellman, M., Laaksonen, P., Linder, M.B., Hirvonen, J., Laaksonen, T., 2013. Evaluation of drug interactions with nanofibrillar cellulose. European Journal of Pharmaceutics and Biopharmaceutics 85, 1238-1244.

Krivosheeva, O., Dėdinaitè, A., Linder, M.B., Tilton, R.D., Claesson, P.M., 2013. Kinetic and equilibrium aspects of adsorption and desorption of class II hydrophobins HFBI and HFBII at silicon oxynitride/water and air/water interfaces. Langmuir 29, 2683-2691. 
Lin, N., Dufresne, A., 2014. Nanocellulose in biomedicine: Current status and future prospect. European Polymer Journal 59, 302-325.

Linder, M.B., Szilvay, G.R., Nakari-Setälä, T., Penttilä, M.E., 2005. Hydrophobins: the proteinamphiphiles of filamentous fungi. FEMS Microbiol. Rev. 29, 877-896.

Linder, M.B., 2009. Hydrophobins: Proteins that self assemble at interfaces. Current Opinion in Colloid \& Interface Science 14, 356-363.

Llinàs, M., Calderó, G., García-Celma, M.J., Patti, A., Solans, C., 2013. New insights on the mechanisms of drug release from highly concentrated emulsions. J. Colloid Interface Sci. 394, 337345.

Lumsdon, S.O., Green, J., Stieglitz, B., 2005. Adsorption of hydrophobin proteins at hydrophobic and hydrophilic interfaces. Colloids and Surfaces B: Biointerfaces 44, 172-178.

Maa, Y., Hsu, C.C., 1999. Performance of sonication and microfluidization for liquid-liquid emulsification. Pharm. Dev. Technol. 4, 233-240.

Malcolmson, C., Satra, C., Kantaria, S., Sidhu, A., Lawrence, M.J., 1998. Effect of oil on the level of solubilization of testosterone propionate into nonionic oil-in-water microemulsions. J. Pharm. Sci. 87, 109-116.

Malinen, M.M., Kanninen, L.K., Corlu, A., Isoniemi, H.M., Lou, Y., Yliperttula, M.L., Urtti, A.O., 2014. Differentiation of liver progenitor cell line to functional organotypic cultures in 3D nanofibrillar cellulose and hyaluronan-gelatin hydrogels. Biomaterials 35, 5110-5121.

Märtson, M., Viljanto, J., Hurme, T., Laippala, P., Saukko, P., 1999. Is cellulose sponge degradable or stable as implantation material? An in vivo subcutaneous study in the rat. Biomaterials 20, 19891995.

Miyamoto, T., Takahashi, S., Ito, H., Inagaki, H., Noishiki, Y., 1989. Tissue biocompatibility of cellulose and its derivatives. J. Biomed. Mater. Res. 23, 125-133.

Nechyporchuk, O., Belgacem, M.N., Pignon, F., 2014. Rheological properties of micro/nanofibrillated cellulose suspensions: Wall-slip and shear banding phenomena. Carbohydr. Polym. $112,432-439$.

Pääkkö, M., Ankerfors, M., Kosonen, H., Nykänen, A., Ahola, S., Österberg, M., Ruokolainen, J., Laine, J., Larsson, P.T., Ikkala, O., 2007. Enzymatic hydrolysis combined with mechanical shearing and high-pressure homogenization for nanoscale cellulose fibrils and strong gels.

Biomacromolecules 8, 1934-1941.

Paananen, A., Ercili-Cura, D., Saloheimo, M., Lantto, R., Linder, M.B., 2013. Directing enzymatic cross-linking activity to the air-water interface by a fusion protein approach. Soft Matter 9, 16121619.

Rege, B.D., Yu, L.X., Hussain, A.S., Polli, J.E., 2001. Effect of common excipients on Caco-2 transport of low-permeability drugs. J. Pharm. Sci. 90, 1776-1786. 
Rege, B.D., Kao, J.P.Y., Polli, J.E., 2002. Effects of nonionic surfactants on membrane transporters in Caco-2 cell monolayers. European Journal of Pharmaceutical Sciences 16, 237-246.

Rouabhia, M., Asselin, J., Tazi, N., Messaddeq, Y., Levinson, D., Zhang, Z., 2014. Production of biocompatible and antimicrobial bacterial cellulose polymers functionalized by RGDC grafting groups and gentamicin. ACS applied materials \& interfaces 6, 1439-1446.

Saito, T., Kimura, S., Nishiyama, Y., Isogai, A., 2007. Cellulose nanofibers prepared by TEMPOmediated oxidation of native cellulose. Biomacromolecules 8, 2485-2491.

Saito, T., Nishiyama, Y., Putaux, J., Vignon, M., Isogai, A., 2006. Homogeneous suspensions of individualized microfibrils from TEMPO-catalyzed oxidation of native cellulose.

Biomacromolecules 7, 1687-1691.

Sarparanta, M.P., Bimbo, L.M., Mäkilä, E.M., Salonen, J.J., Laaksonen, P.H., Helariutta, A.M.K., Linder, M.B., Hirvonen, J.T., Laaksonen, T.J., Santos, H.A., Airaksinen, A.J., 2012. The mucoadhesive and gastroretentive properties of hydrophobin-coated porous silicon nanoparticle oral drug delivery systems. Biomaterials 33, 3353-3362.

Sharif Makhmalzadeh, B., Torabi, S., Azarpanah, A., 2012. Optimization of ibuprofen delivery through rat skin from traditional and novel nanoemulsion formulations. Iranian Journal of Pharmaceutical Research 11, 47-58.

Singh, A., Worku, Z.A., Van den Mooter, G., 2011. Oral formulation strategies to improve solubility of poorly water-soluble drugs. Expert opinion on drug delivery 8, 1361-1378.

Strickley, R.G., 2004. Solubilizing excipients in oral and injectable formulations. Pharm. Res. 21, 201.

Szilvay, G.R., Paananen, A., Laurikainen, K., Vuorimaa, E., Lemmetyinen, H., Peltonen, J., Linder, M.B., 2007. Self-assembled hydrophobin protein films at the air-water interface: structural analysis and molecular engineering. Biochemistry (N. Y. ) 46, 2345-2354.

Valo, H.K., Laaksonen, P.H., Peltonen, L.J., Linder, M.B., Hirvonen, J.T., Laaksonen, T.J., 2010. Multifunctional hydrophobin: toward functional coatings for drug nanoparticles. ACS nano 4, 17501758.

Valo, H., Arola, S., Laaksonen, P., Torkkeli, M., Peltonen, L., Linder, M.B., Serimaa, R., Kuga, S., Hirvonen, J., Laaksonen, T., 2013. Drug release from nanoparticles embedded in four different nanofibrillar cellulose aerogels. European Journal of Pharmaceutical Sciences 50, 69-77.

Valo, H., Kovalainen, M., Laaksonen, P., Häkkinen, M., Auriola, S., Peltonen, L., Linder, M., Järvinen, K., Hirvonen, J., Laaksonen, T., 2011. Immobilization of protein-coated drug nanoparticles in nanofibrillar cellulose matrices-Enhanced stability and release. J. Controlled Release 156, 390-397.

Varjonen, S., Laaksonen, P., Paananen, A., Valo, H., Hähl, H., Laaksonen, T., Linder, M.B., 2011. Self-assembly of cellulose nanofibrils by genetically engineered fusion proteins. Soft Matter 7 , 2402-2411. 
1 Vartiainen, J., Pöhler, T., Sirola, K., Pylkkänen, L., Alenius, H., Hokkinen, J., Tapper, U., Lahtinen, 2 P., Kapanen, A., Putkisto, K., 2011. Health and environmental safety aspects of friction grinding 3 and spray drying of microfibrillated cellulose. Cellulose 18, 775-786.

4 Weishaupt, R., Siqueira, G., Schubert, M., Tingaut, P., Maniura-Weber, K., Zimmermann, T., 5 Thöny-Meyer, L., Faccio, G., Ihssen, J., 2015. TEMPO-oxidized nanofibrillated cellulose as a high 6 density carrier for bioactive molecules. Biomacromolecules 16, 3640-3650.

7 Wilde, P., Mackie, A., Husband, F., Gunning, P., Morris, V., 2004. Proteins and emulsifiers at 8 liquid interfaces. Adv. Colloid Interface Sci. 108-109, 63-71.

9 Woodcock, D.M., Linsenmeyer, M.E., Chojnowski, G., Kriegler, A.B., Nink, V., Webster, L.K., 10 Sawyer, W.H., 1992. Reversal of multidrug resistance by surfactants. Br. J. Cancer 66, 62-68. Wulff-Pérez, M., Torcello-Gómez, A., Gálvez-Ruíz, M.J., Martín-Rodríguez, A., 2009. Stability of emulsions for parenteral feeding: Preparation and characterization of $\mathrm{o} / \mathrm{w}$ nanoemulsions with natural oils and Pluronic f68 as surfactant. Food Hydrocoll. 23, 1096-1102. 